\title{
GPS Satellite Interference in Hungary
}

\author{
T. Borza and I. Fejes \\ FÖMI Satellite Geodetic Observatory, H-1373 Budapest, Pf. 546, \\ Hungary
}

\begin{abstract}
Civil users of the NAVSTAR Global Positioning System (GPS) in Hungary occasionally experience interference at the 1575.42$\mathrm{MHz}$ GPS signal frequency. As the application of the GPS technique spreads rapidly in our country, radio frequency interference (RFI) should be considered a serious threat. The new geodetic control network (OGPSH) in Hungary is based on GPS measurements and incorporates more than 1100 sites. The paper reports the experiences gained during the establishment of the network. Interference sources were tracked to groundbased digital data transmissions for telecommunications, which operate mostly in the Western part of Hungary. Telecommunication regulations exceptionally allow such transmissions in specified countries. In order to warn potential GPS users, the interference sources are being mapped.
\end{abstract}

\section{Introduction}

Radio frequency interference (RFI) can seriously affect GPS applications, particularly in geodetic field work. In such cases, the unsuspecting operators of geodetic GPS receivers may experience lock-on failures, nonsense error messages or total malfunctioning of their receivers. Several authors have already reported GPS interference in different countries (e.g. Butsch 1997, Haagmans 1994). In this paper we report such disturbances from Hungary. Identification and mapping of the interference sources is of national interest in order to inform GPS users about potential dangers.

In 1995 and 1997 a GPS-based geodetic control network (OGPSH) was established, consisting of more than 1100 sites well distributed in the territory of Hungary. The average distance between the sites is about $10 \mathrm{~km}$. During the field measurements, our engineers experienced "inexplicable" receiver failures at some locations, which later proved to be caused by RFI. In this paper we report our preliminary investigations and identify some of the interference sources. Clearly more detailed study of the GPS interference problem is necessary to map RFI disturbing GPS applications in the country.

\section{Spectral Measurements}

We received 10 reports of receiver failures, which we decided to investigate in more detail. In these cases the receivers were failing in certain locations, whereas 


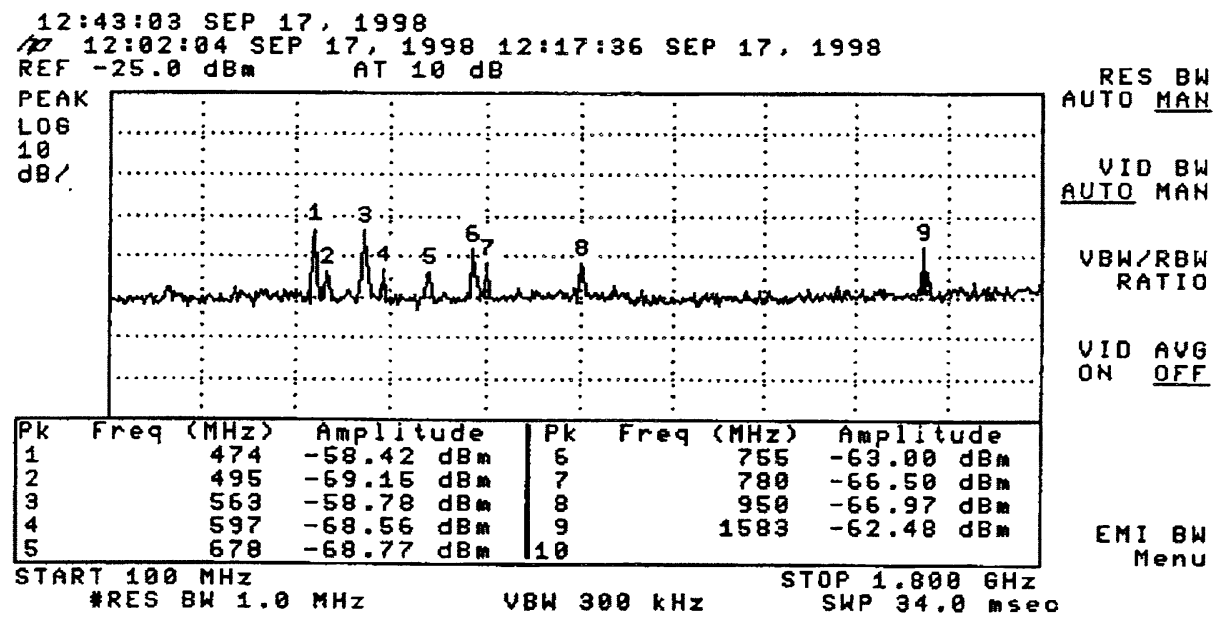

Figure 1. $1700 \mathrm{MHz}$ wide-band spectrum obtained near Lentikápolna using the horn antenna without preamplifier. Interference peaks are numbered.

on moving them to another place, the receiver operations were normal. This was a clear indication of RFI. In the interval March - September 1998 we inspected the reported locations using Trimble $4000 \mathrm{SSE}$, Trimble $4000 \mathrm{SST}$, Trimble Pathfinder ProXL and handheld Trimble Scout type GPS receivers. We found serious receiver failures at two locations: near Zalalövő and near Lentikápolna. According to these tests the most sophisticated geodetic receiver (SSE) was the most sensitive to interference while the handheld navigation receiver (Scout) was the least affected in operation. Susceptibility of GPS receivers to RFI has been investigated e.g. by Sluiter and Haagmans (1995).

In September 1998, in collaboration with the Technical University of Budapest, spectral measurements were carried out at Zalalövő and Lentikápolna locations using a Hewlett Packard 8790L type spectrum analyser. Two different antennae were applied. The first one was a wide-band horn antenna without preamplifier. The second was a SEL Alcatel Globos M2000 type GPS antenna equipped with narrow-band filter and preamplifier.

Figure 1. shows a wide-band spectrum in the range $100-1800 \mathrm{MHz}$, obtained with the first antenna at Lentikápolna. Several peaks can be identified. The peaks below $1 \mathrm{GHz}$ were not pursued further, since their harmonics were not considered to be harmful for GPS signal reception. The peak No. 9 at $1583 \mathrm{MHz}$, however, falls very close to the GPS L1 signal at $1575.42 \mathrm{MHz}$. Therefore it deserved a closer look.

Figure 2. shows a $200 \mathrm{MHz}$ wide spectrum centred on $1584 \mathrm{MHz}$. Peaks of transmissions at $1562.5,1576.5,1582.5,1587.0,1595.0$ and at $1607.0 \mathrm{MHz}$, with levels in the range -24.54 to $-58.74 \mathrm{dBm}$, are clearly identified. The peaks are superposed on a more than $50 \mathrm{MHz}$ wide-band signal at about $-60 \mathrm{dBm}$. These signals overlap the GPS L1 frequency range. 


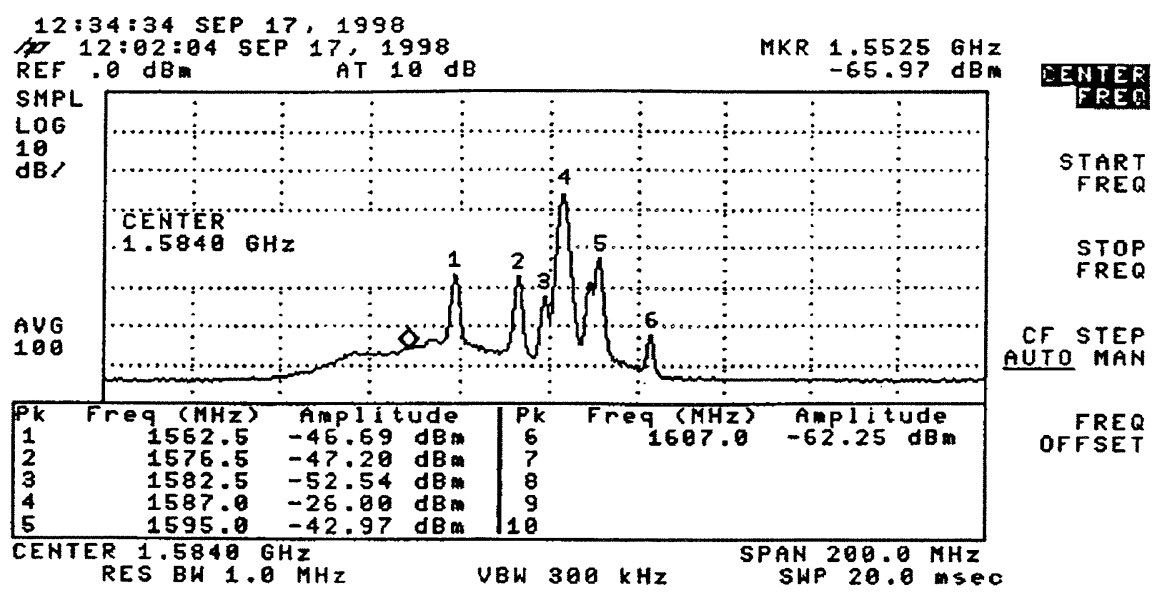

Figure 2. RFI spectrum overlapping the GPS L1 (1575.42 MHz) frequency near Lentikápolna. Interference peaks are numbered.

Figure 3. shows a $710 \mathrm{MHz}$ wide spectrum obtained near Zalalövő, centred on $1584 \mathrm{MHz}$. Peaks of transmissions at $1566.4,1582.3$ and at $1591.2 \mathrm{MHz}$, with levels in the range -34.41 to $30.67 \mathrm{dBm}$, are clearly identified. Here again the peaks are superposed on a more than $50 \mathrm{MHz}$ wide-band signal at about $-60 \mathrm{dBm}$ level. These signals overlap the GPS L1 frequency range. The signal structure is characteristic of digital data transmission. Using the directional sensitivity of the GPS antenna we identified a nearby fixed telecommunication tower as the source of the signal. The disturbing transmission was clearly directional, since, on moving the receivers by a few hundred meters, the interference disappeared.

\section{Are Ground-to-Ground Transmissions Legal at the L1 Frequency?}

According to the Radio Regulations of the International Telecommunication Union (ITU RR) the $1559-1610 \mathrm{MHz}$ frequency band is primarily allocated to Aeronautical Radionavigation and Space-Earth Radionavigation-Satellite Services. But this regulation is complemented with a footnote, which adds:

"Additional allocation: in the Federal Republic of Germany, Austria, Bulgaria, Cameroon, Guinea, Hungary, Indonesia, Libya, Mali, Mongolia, Nigeria, Poland, the German Democratic Republic, Romania, Senegal, Czechoslovakia and U.S.S.R., the bands $1550-1645.5 \mathrm{MHz}$ and $1646.5-1660 \mathrm{MHz}$ are also allocated to the fixed service on a primary basis."

So MATÁV uses these frequencies legally and according to the ITU regulations. This means that the L1 GPS signal frequency is not protected in the listed countries, including Hungary.

We have contacted the Hungarian Communication Authority (HCA) asking for more information about this matter. The HCA kindly provided a detailed 


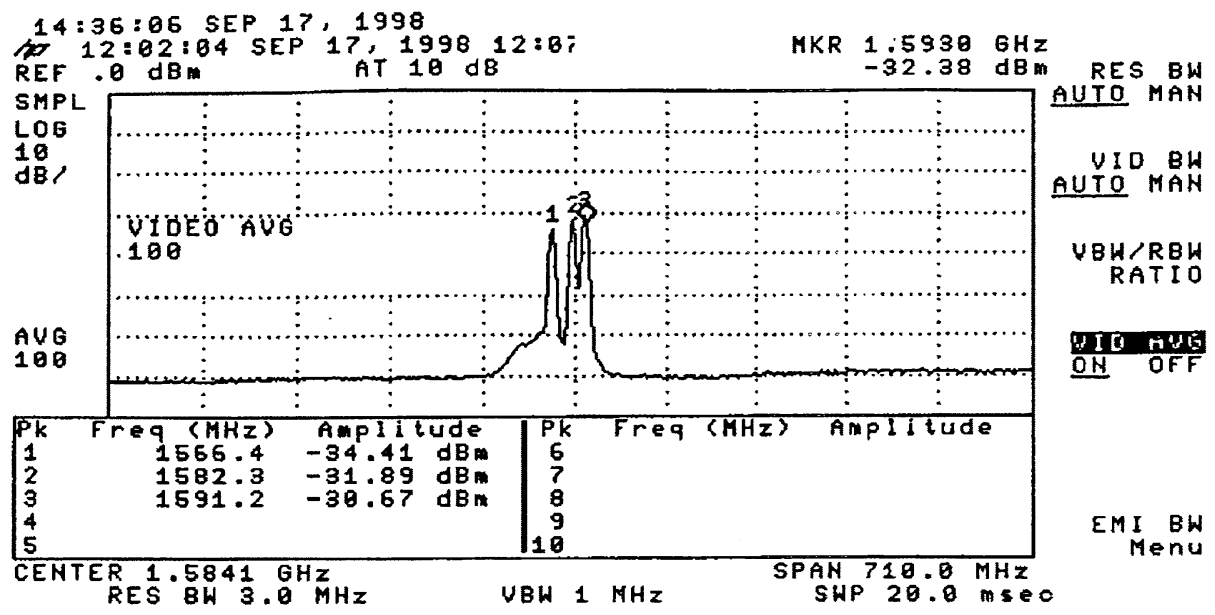

Figure 3. RFI spectrum overlapping the GPS L1 $(1575.42 \mathrm{MHz})$ frequency near Zalalövő. Interference peaks are numbered.

list of transmitters operating in this frequency band. The HCA also informed us that Hungary is preparing steps to protect the band $1574.5-1576.5 \mathrm{MHz}$ for the sake of GPS users. For the fixed services, new licences will not be issued, and existing licences will not be extended in Hungary. A considerable decrease in the number of cases of interference originating from fixed services on the L1 frequency is projected for the coming years.

\section{Mapping GPS Interference Sources in Hungary}

According to the list provided by the HCA, we have found 60 fixed stations operating near the GPS L1 frequency. Figure 4. shows the geographic distribution of these stations in Hungary. The stations dominantly cluster in the Western part of the country, but some can be found South of Pécs and also near the river Tisza in Eastern Hungary.

The precise geographic extension of the RFI around the towers has not yet been mapped. In the course of OGPSH measurements we had to change the position of 3 preplanned sites out of 1150 due to interference. This seems a surprisingly small proportion. Nevertheless, we plan to carry out more detailed investigation of this problem and continue to collect information on GPS interference sources in Hungary.

\section{Planned Activities}

We intend to collect countrywide information on the RFI experienced by Hungarian GPS users. More detailed mapping of the extent of interference near the listed transmitters is necessary in order to assess the dangers for GPS users. 


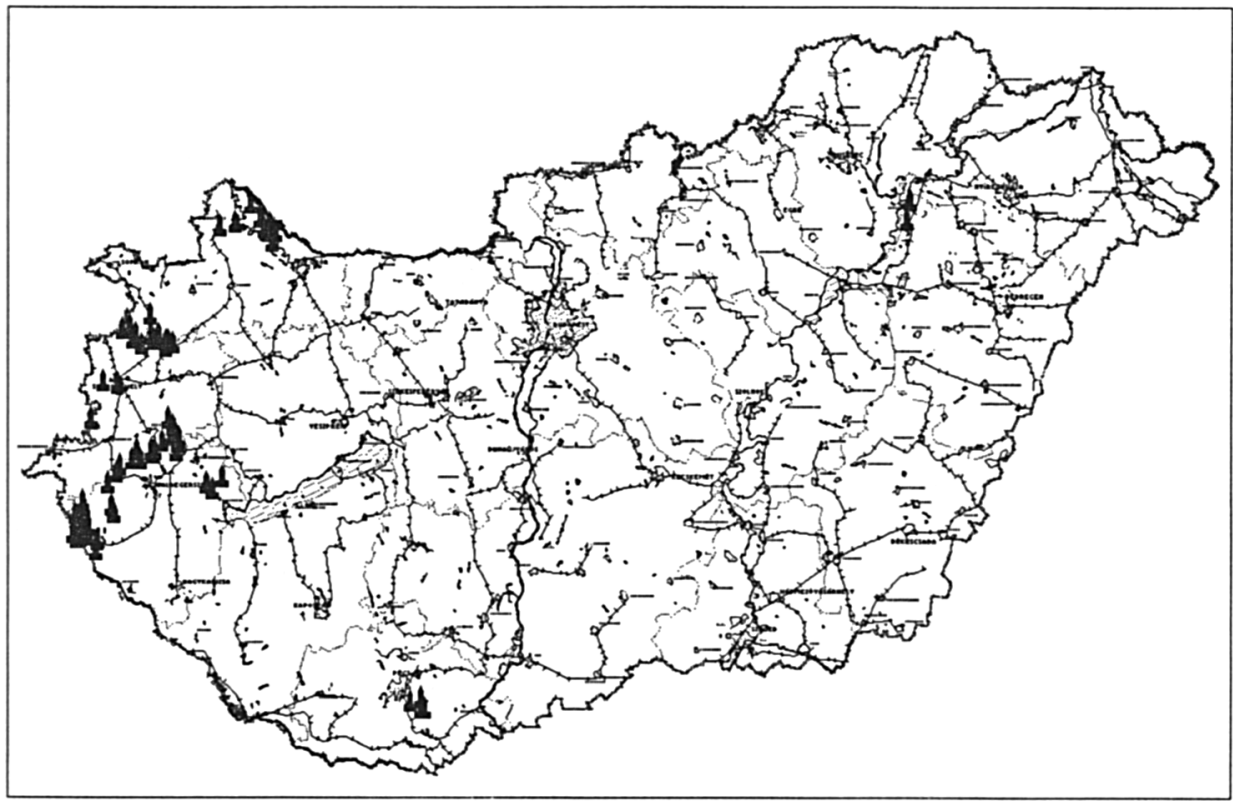

Figure 4. Fixed transmitters operating in Hungary in the frequency band $1560-1610 \mathrm{MHz}$.

Therefore further systematic spectral measurements are necessary. The sensitivity of different GPS receiver types to RFI will be another topic for study. We are aware of the fact that fighting interference is a continuing struggle and new RFI sources can appear unexpectedly anytime, anywhere.

Acknowledgments. The authors thank G. Ijjas (TU Budapest) for contributions to the spectral measurements and P. Tomka (HCA) for providing helpful information on fixed transmitters. This work was supported by the Ministry of Transport, Communication and Water Management under contract HEKI 288/A.

\section{References}

Butsch, F. 1997, GPS interference problems in Germany. Proc. ION Annual Meeting, Abuquerque, N.M., USA.

Haagmans, M.E.E. 1994, GPS signal reception problems: the situation in the Netherlands. GPS Niusbrief, May 1994, p. 67-69

Sluiter, P.G., Haagmans, M.E.E. 1995, Comparative test between geodetic Ycode GPS receivers. Susceptibility to radio frequency interference. GPS Niewsbrief, May 1995, p. 11-17 